\title{
Compensatory Fuzzy Logic Uses in Business Indicators Design
}

\author{
MsC. Ing. Pablo Michel Marin Ortega ${ }^{1}$, Ms.C. Ing. Patricia Pérez Lorences ${ }^{1}$, Dr.-Ing. habil. Jorge Marx \\ Gómez ${ }^{2}$ \\ ${ }^{1}$ Central University of Las Villas, Santa Clara, Cuba \\ pablomo@uclv.edu.cu,patriciapl@uclv.edu.cu, jorge.marx.gomez@uni-oldenburg.de
}

\begin{abstract}
Most of the information needed for the management in the decision making process is essentially based on subjective and imprecise concepts expressed primarily by "experts" in a natural language or based in simples indicators and it's not capable to check the strategy in a more integral way. In the present research we show two application of the compensatory fuzzy logic to resolve the problem mentioned above. As the main contributions we show first an aggregation method to design new indicators based on the statistic and compensatory fuzzy logic approach and as second we define a new indicator to measure the IT governance level.
\end{abstract}

Keywords: Compensatory Fuzzy Logic, IT governance, aggregation methods

\section{Introduction}

In the search for competitiveness, the companies are pursuing different strategies for finding sustainable advantages in the competitive environment in which they develop. According to Porter, the advantages can come from two aspects: operational effectiveness and unique value creation for customers.

Both ways to generate competitive involve designing the structure and business activities in a systemic way and unique combination, which makes them hard to match, which must be sustained in the flexibility and adjustment speed in front of changes.

The strategic management tools help to monitoring the strategic actions in a more comprehensive and simple way. However, from the review of its implementation can be noticed among the main shortcomings: the absence of indicators capable of monitoring the strategy in a more integral way and most of the information needed for its design is essentially based on subjective and imprecise concepts expressed primarily by "experts" in a natural language.

The Compensatory Fuzzy Logic is an area that can fill these gaps largely because it uses language as a communication, it create an explicit model of preferential knowledge and then use the inference capability of the logical platform to propose decisions that better reflect the decision policy of individuals.

This paper is organized as follows: Section 2 provides related work. In Section 3, we present a methodology to implement a fuzzy aggregation method and show some partial results. In Section 4 we present a fuzzy indicator for IT governance assessing. Finally, conclusions and future work are discussed in Section 5.

\section{Related word}

The fuzzy logic is a multivalent system used in the modeling of problems where they need to handle vague or hard to specify information (Konar, 2000). It was investigated for the first time in the mid-sixties at the University of Berkeley (California) by engineer Lotfi Asker Zadeh. He introduced then the concept of fuzzy set under which resides the idea that the elements on which human thinking is built are not numbers but linguistic labels. Fuzzy logic allows us to represent the common knowledge (which is mostly of qualitative linguistic and not necessarily quantitative) in a mathematical language through the fuzzy set theory and characteristic functions associated with them. Example of its application can be seen in expressions like "that man is tall", "today's hot" or "I will take a while". However it is not so easy to define what is meant by "high", "heat" or "a while" because it will be difficult to specify at which height a person can be considered high, or from what temperature is said to be hot, or how long it means waiting a while (Ceruto Cordovés, 2009).

Fuzzy logic works with data sets like ones above, where there are no well-defined limits. The fuzzy logic use expressions that are neither completely true nor completely false, it applies to concepts that can take any value of accuracy within a set of values ranging between two extremes, the absolute truth and complete falsehood. The whole idea is that things are not black or white, but there are infinite shades of gray.

One way to implement the "principle of gradualism", essential property of fuzzy logic, is the definition of logics where the predicates are functions of the universe $\mathrm{X}$ in the interval $[0,1]$ and the operations of conjunction, disjunction, negation, and implication, are defined so that when restricted to the domain (Marin Ortega, 2009) you 
get the Boolean Logic. The different ways of defining the operations and their properties determine different multivalent logics that are part of the Paradigm of Fuzzy Logic (Dubois D. y Prade, 1980).

However, this system has not fully facilitated the task of modeling the knowledge in a natural way, for which reason is common in applications using Fuzzy Logic, the use of free operators together with an extralogical resource called unfuzzyfication (Espín, 2007 a). The use of language as a communication element between an analyst and a decision-maker in the way that often arises between a Knowledge Engineering and an Expert indicates as noted above more to the use of a harmonious combination of operators, than towards the use of only one of them. The main characteristics that makes it difficult to use logicbased approaches in decision modeling are (Espín Andrade):

The associative property of conjunction and disjunction operators used.

The total lack of compensation for the truth values of basic predicates when calculating the accuracy of compound predicates using the operators.

The elements explained in (Espín Andrade) suggest that for application to decision making, it is desirable to create non-associative multivalent logic systems, and facilitate the compensation of the truth values of the basic predicates with each others. The Compensatory Fuzzy Logic (CFL) is a variant of the Fuzzy Logic that overcomes the previous difficulties. The axiomatic behavior of CFL makes feasible its use in decision making and knowledge discovery (Espín, 2009 a ). This is why, it is proposed as a logical approach of the decision, which joins the decision modeling and the reasoning.

\section{Methodology to implement a fuzzy aggregation method}

The methodology to implement a fuzzy aggregation method is compound by nine steps; each one is described as follows:

Step 1 Development of a conceptual framework: the main goal of this step is to choose an indicator's set for each perspective in the IT BSC from the indicators defined on the COBIT processes. The analyst must take into account the IT BSC mission and objectives described above; to achieve this goal we propose a possible mapping among the IT BSC perspective and COBIT domains.

Step 2 Indicators historical data: the main idea for this step is to collect all the historical data for each indicator chosen in the previous step, and based on the quantity of each one the analyst must answer the follow question: Is there historical data for each indicator to perform a statistical analysis? In(Nardo et al., 2005, Little and Rubin, 2002) was defined an empiric rules set, these are show as following:

- Rule 10: to have at least 10 samples for each indicator.
- Rule 3:1: the samples should be the triple of the indicators to analyze.

- Rule 5:1: the relation between samples and variables must be five to one.

- Rule 100: the samples should be five times the indicator's quantity and higher than 100 .

- Rule 150: to have more than 150 samples for each indicator when the correlation among the indicators is low.

- Rule 200: to have more than 200 samples for each indicator, without taking into account the amount of variables.

- Rule of the significance: to have 51 more samples than the indicator's quantity, with the purpose of running the chi-squared test.

Sometimes in the enterprise there is not historical data to develop a statistical analysis for each indicator, in this case the analyst can: 1) exclude the indicator from the analysis but if according with the expert criteria the indicator is very important in the analysis then we must to include it and proceed according to step three or 2) to use a forecasting method to generate the necessary data(this option is applicable if there is some historical data and is only necessary to create a few data samples to fulfill the previous rules).

Step 3 Imputation of missing data: Sometimes we have missing data in the indicators under study; it can affect the final result of global indicators, in (Little and Rubin, 2002)were showed four solutions for this problem:

(i) Remove the information: in this case we should hide the item from the analysis, it can increase the dispersion.

(ii) Delete the indicator in the analysis: in this case we should remove the indicator from the analysis. We must to take into account that if the indicator missing values is less than five percent of all indicators then we can't remove it from the analysis.

(iii) Single imputation data: we can use statistical methods like average, median, mode or regression based on the available data.

(iv) Multiple imputations: in this case we can use the Monte Carlo algorithms and Markov chains.

To achieve this step we can use software like: SPSS, Microsoft Excel, Weka, R-Studio.

Step 4 Principal Component Analysis (PCA): the main goal in this step is to know how we can group the indicators to build a global indicator based on the statistical analysis. The algorithm was created by (Pearson, 1901) from a geometric approach and afterwards in (Hotelling, 1993, Kaiser, 1958)was defined in an algebraic approach. The algorithm ensures the maximum correlation among the items in the component and minimum correlation among the components, it is an important remark because sometimes it is necessary to define a weight for each indicator or component according with the organization goals or the experts criteria; and if there is relation among components then the indicators within each com- 
ponent will be overweighed. In this step the analyst should validate that the Correlation Matrix's Determinant should be near to zero and the Kaiser-Meyer-Olk in Measure of Sampling Adequacy should be more than 0.5. In the case that any of this parameters is wrong then we advise to use other extraction methods like: Generalized Least Squares, Maximum Likelihood, Alpha Factoring or Unweighted Least Squares where the previous parameters are acceptable.

To achieve this step we can use software like: SPSS, Weka, R-Studio.

Step 5 Internal consistency test: Once we have defined the possible indicators set in each component, it is important to validate the not existents spurious relation among the indicators into a group, to do it we propose to use Cronbach's alpha test (Cronbach, 1951). The final value result from the test should be near to one, even though a result higher than 0.7 is acceptable. Also we advise to re-calculate the coefficient excluding one indicator per time and if the coefficient value is higher than the previous one then it means that there is spurious relation and we should remove the indicators from the component.

Step 6 Choose components: the main goal in this step is validate according with the expert criteria if the component (global indicator) is a good measuring to measure the goals accomplish.

Step 7 Indicator fuzzification: Every time we want to build new indicators based on aggregation methods is important to normalize the indicators. Under the principles stated above and using compensatory fuzzy logic as an aggregation method we propose to do it using a sigmoidal membership function, because, by theoretical considerations in (Dubois and Prade, 1985), it is recommend the use of sigmoidal membership functions for increasing or decreasing functions. The parameters of these functions are determined by setting two values. The first is the value at which it is considered that the statement in the predicate is true (gamma). The second is the value for which the data makes almost unacceptable the corresponding statement (beta) (Ceruto Cordovés et al., 2009). The sigmoidal membership function is calculated as follows:

$$
\begin{aligned}
& \mathrm{S}(\mathrm{x}, \alpha, \gamma)_{\mathrm{k}}=\frac{1}{1+\mathrm{e}^{-\alpha\left(\mathrm{x}_{\mathrm{k}}-\gamma\right)}} \\
& \alpha=\frac{\ln (0.9)-\ln (0.1)}{\gamma-\beta}
\end{aligned}
$$

Where:

S: Value of truth of the criterion of measurement of indicator "k"

$\mathrm{X}$ : Calculated value of the indicator " $\mathrm{k}$ " according to the company

Gamma $(\gamma)$ : Value acceptable. It would be equal to the value at which the indicator is considered acceptable.

Beta $(\beta)$ : Value almost unacceptable: It would be equal to the pre-image of a symmetric sigmoidal function for the optimal value defined for the indicator, or it would be the same $\beta=$ (Value at which the indicator is acceptable Value from which the indicator is optimal).
Alfa $(\alpha)$ : Sigmoidal function parameter. View expression 2 .

Step 8 Indicator's importance by component: Sometimes the indicators have different weights according with the organization's goals, for this reason in this step the expert should define a weight for each indicator by global indicator. The scale to define the weighs will be continuous number among $[0,1]$.

Step 9 Aggregation fuzzy methods: A global indicator is build taking into account the weight for each simple indicator and its value of truth (see expression 1). Under the principles stated above and using compensatory fuzzy logic to compensate the global indicator, would be defined as follows:

$$
\mathrm{GI}_{\mathrm{i}}=\underset{\mathrm{j}=1}{\mathrm{j}=\mathrm{n}}\left[\mathrm{W}_{\mathrm{j}} \rightarrow \mathrm{V}_{\mathrm{j}}\right] \in[0,1]
$$

Where:

GIi: Value of truth of the global indicator "i"

Wj: Weight of the " $\mathrm{j}$ " simple indicator

$\mathrm{Vj}$ : Value of truth of the simple indicator " $\mathrm{j}$ ". See expression 1.

The result set from the expression 3 will be a continuo's number among $[0,1]$ where one is the optimal result and zero the worst result.

The performance of the proposed method and its algorithms are evaluated using a set of $20 \mathrm{KPI}$. As you can see in the table 2 with three global indicators we explain near to the $80 \%$ of the total variance. The Cronbach's alpha test is show in the table 3, and you can see the result is greater than 0.7. According with the result we model the global indicator in the Fuzzy Tree Studio Software (see Fig. 1).

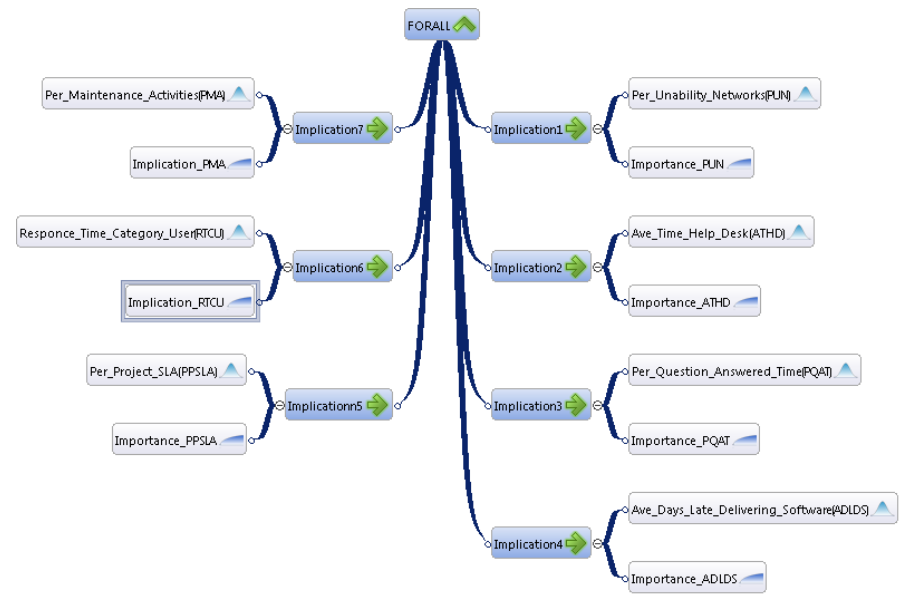

Fig. 1: Fuzzy tree to calculate a global indicator

Once defined the indicators for each BSC, we can design the ETL process and also define the OLAP, ad hoc and standard reports. 
Table 1: Total Variance Explained

\begin{tabular}{|c|c|c|c|c|c|c|}
\hline \multirow[t]{2}{*}{ Component } & \multicolumn{3}{|c|}{ Initial Eigenvalues } & \multicolumn{3}{|c|}{ Extraction Sums of Squared Loadings } \\
\hline & Total & \% of Variance & Cumulative \% & Total & \% of Variance & Cumulative \% \\
\hline 1 & 8.186 & 38.979 & 38.979 & 8.186 & 38.979 & 38.79 \\
\hline 2 & 5.982 & 28.487 & 67.466 & 5.982 & 28.487 & 67.466 \\
\hline 3 & 2.569 & 12.233 & 79.700 & 2.569 & 12.233 & 79.700 \\
\hline 4 & .957 & 4.557 & 84.257 & & & \\
\hline 5 & .899 & 4.282 & 88.539 & & & \\
\hline 6 & .674 & 3.210 & 91.749 & & & \\
\hline 7 & .463 & 2.203 & 93.952 & & & \\
\hline 8 & .309 & 1.473 & 95.426 & & & \\
\hline 9 & .263 & 1.252 & 96.678 & & & \\
\hline 10 & .228 & 1.086 & 97.763 & & & \\
\hline 11 & .175 & .834 & 98.598 & & & \\
\hline 12 & .116 & .551 & 99.148 & & & \\
\hline 13 & .082 & .389 & 99.537 & & & \\
\hline 14 & .041 & .196 & 99.733 & & & \\
\hline 15 & .022 & .105 & 99.839 & & & \\
\hline 16 & .020 & .096 & 99.935 & & & \\
\hline 17 & .013 & .061 & 99.996 & & & \\
\hline 18 & .000 & .002 & 99.998 & & & \\
\hline 19 & .000 & .001 & 99.999 & & & \\
\hline 20 & .000 & .000 & 100.000 & & & \\
\hline
\end{tabular}

Table 2: Reliability Statistics

\begin{tabular}{|c|c|c|c|c|c|c|}
\hline Cronbach's Alpha & \multicolumn{3}{|c|}{ Cronbach's Alpha Based on Standardized Items } & \multicolumn{3}{|l|}{$\mathrm{N}$ of Items } \\
\hline .846 & \multicolumn{3}{|c|}{.998} & \multicolumn{3}{|l|}{7} \\
\hline \multicolumn{7}{|c|}{ Item-Total Statistics } \\
\hline & & $\begin{array}{l}\text { Scale Mean } \\
\text { if Item De- } \\
\text { leted }\end{array}$ & $\begin{array}{l}\text { Scale Vari- } \\
\text { ance if Item } \\
\text { Deleted }\end{array}$ & $\begin{array}{l}\text { Corrected Item- } \\
\text { Total Correla- } \\
\text { tion }\end{array}$ & $\begin{array}{l}\text { Squared } \\
\text { Multiple } \\
\text { Correlation }\end{array}$ & $\begin{array}{l}\text { Cronbach's } \\
\text { Alpha if } \\
\text { Item Delet- } \\
\text { ed }\end{array}$ \\
\hline \multicolumn{2}{|c|}{ Percentage Unavailability of Network } & 94561.59854 & $3.406 \mathrm{E} 11$ & .997 & .994 & .867 \\
\hline \multicolumn{2}{|c|}{ Average Answer Time of Help Desk } & 94854.26788 & $3.431 \mathrm{E} 11$ & .959 & .947 & .870 \\
\hline \multicolumn{2}{|c|}{$\begin{array}{l}\text { Percentage of Questions Answered } \\
\text { Within Time }\end{array}$} & 65430.59557 & $1.681 \mathrm{E} 11$ & 1.000 & 1.000 & .747 \\
\hline \multicolumn{2}{|c|}{$\begin{array}{l}\text { Average Days Late In Delivering } \\
\text { Software }\end{array}$} & 89758.93064 & $3.111 \mathrm{E} 11$ & 1.000 & 1.000 & .839 \\
\hline \multicolumn{2}{|c|}{$\begin{array}{l}\text { Percentage of Projects Performed } \\
\text { Within Sla }\end{array}$} & 69306.59726 & $1.678 \mathrm{E} 11$ & 1.000 & 1.000 & .747 \\
\hline \multicolumn{2}{|c|}{ Percentage Of Maintenance Activities } & 65619.06807 & $1.680 \mathrm{E} 11$ & 1.000 & 1.000 & .747 \\
\hline \multicolumn{2}{|c|}{$\begin{array}{l}\text { Response Times Per Category Of Us- } \\
\text { ers }\end{array}$} & 89760.79859 & $3.111 \mathrm{E} 11$ & 1.000 & 1.000 & .839 \\
\hline
\end{tabular}




\section{Fuzzy indicator for IT governance assessing}

According the literature review IT governance has two fundamental edges: strategic alignment of IT to business objectives and IT risk management. Also must be considered the implementation of good practices and the IT organization including organizational structures, processes and responsibilities defined. The verbal formulations of a fuzzy logic global model proposed to evaluate the level of IT governance is:

A company has a high level of IT governance if 1) the level of IT organization within the company is solid and 2 ) is a very high degree of strategic alignment between IT and business and 3) is very high level the IT risk management and 4) the level of implementation of good IT management is high.

The above can be expressed using Compensatory Fuzzy Logic as follows:

NGTI = OTI $\cap$ AETI $\cap$ GRTI $\cap$ IBPTI

Where:

NGTI: value of truth in IT governance level

OTI: value of truth in IT organization level

AETI: value of truth in IT Business Alignment

GRTI: value of truth in IT risk management level

IBPTI: value of truth in the implementation level of IT governance good practices

This compound predicate model is detailed below:

(i) A company has a solid level of IT organization if :

- The degree of responsibility definition is high if there is a maximum charge of IT and is a member of the board of directors.

- The degree of organizational structures definition is high if the IT function is located in the organization of the company and there is a group or department, and the roles and responsibilities of each member are defined and assigned.

OTI $=($ RTI $\cap$ CD) $\cap($ FTI $\cap$ GGTI $\cap$ RR) $\cap$ PGTI ... (5)

Where:

RTI: value of truth in the existence of a IT highest responsible in the company

$\mathrm{CD}$ : value of truth that IT manager is a member of the Governing Board

FTI: value of truth that IT function is located in the organizational chart

GGTI: value of truth in the existence of a IT group or department

RR: value of truth of roles and responsibilities are defined and assigned

PGTI: value of truth of IT management process is defined

(ii) A company has very high degree of strategic alignment between IT and the business if IT performance is sufficiently addressed in the Board and

(iii) There is a strong level between IT strategies and business strategies if the degree of definition and implementation of IT strategies is very high, taking into account the business strategies for defining and both strategies are strongly related.

AETI $=$ DTI $\cap($ GDIETI $\cap$ EE $\cap$ REEGDI) $\cap$ FETI $\cap$ FSTI . . (6)

Where:

DTI: value of truth that IT performance is sufficiently addressed in the management board

GDIETI: value of truth in the degree of definition and implementation of IT strategies

EE: value of truth that are taken into account enterprise strategies for defining the IT strategies

REEGDI: value of truth in the relationship between business strategy and IT strategy

FETI: value of truth in the delivery frequency of value propositions from IT to business FSTI: value of truth in the demand frequency of new IT projects that add value from business

(iv) A company has very high level of IT risk management if 3.1) this is a priority issue, 3.2) top management participates actively and 3.3) company implements IT risk good practices. If senior management is actively involved then IT risk management is not limited to the Computer Security Responsible.

- 3.1) The IT risk management is a priority issue considering that it is an issue of great importance to the business and IT risks are discussed on the boards to elaborate action plans.

- Senior management is actively involved if is aware of how IT risks can cause damage to the company, involved in the identification of IT risks that affect the achievement of business objectives and evaluates risk mitigation strategies continuously.

- The company implements good practices if assessment and IT risk management follow standard procedures, have been identified IT risks and the potential impact on business objectives, measures are planned to reduce the identified risks and IT risk assessments are made periodically.

GRTI $=($ IRTI $\cap$ RTICD $) \cap(($ CRTI $\cap$ PIRTI $\cap$ EEDRTI $) \rightarrow S E) \cap$ $(\mathrm{PU} \cap \mathrm{IRTIO} \cap \mathrm{PMRTI} \cap \mathrm{ERTI}) . .(7)$

Where:

IRTI: value of truth in the IT risk importance

RTICD: value of truth that IT risks is discussed on the boards to elaborate action plans.

CRTI: value of truth that senior management is aware of how IT risks can cause damage to the company

PIRTI: value of truth that senior management is involved in the identification of IT risks that affect the achievement of business objectives

EEDRTI: value of truth that senior management evaluates IT risk mitigation strategies continuously

SE: value of truth that IT risk management is an issue that is not limited to the Computer Security Responsible

PE: value of truth that company follows standard procedures for assessment and IT risk management

IRTIO: value of truth that IT risks have been identified and its potential impact on business objectives 
PMRTI: value of truth that measures are planned to reduce the identified risks

ERTI: value of truth that IT risk assessments are conducted periodically

4) The level of implementation of good IT governance (ITG) practices is high if they apply international standards and 4.1) there is a high level application of ITG basic practices.

4.1) There is a high level application of ITG basic practices if the Board of Directors reviews the budgets and IT plans regularly, is formed an expert group to assess IT investment projects, are used indicators to monitor IT performance and its contribution to business objectives, the availability and security of IT services is managed according to the priorities of the company, there is a training program for staff involved with IT based on the deficiencies founded in the assessments performance, and IT processes are monitored, evaluated and corrected.

\section{IBPTI $=$ AEIT $\cap($ DRPPTI $\cap$ EEPITI $\cap$ IDTI $\cap$ GDSTI $\cap$ EPC}

กPTIMEC)...(8)

Where:

AEIT: value of truth in applying international standards in IT governance

DRPPTI: value of truth that the Board of Directors reviews the budgets and IT plans regularly.

EEPITI: value of truth that is formed an expert group to assess IT investment projects.

IDTI: value of truth that indicators are used to monitor the IT performance and also its contribution to measure the business objectives.

GDSTI: value of truth that availability and security of IT services its managed according to business priorities.
EPC: value of truth that there is a training program for staff involved in IT based on the deficiencies founded in performance evaluations.

PTIMEC: value of truth that IT processes are monitored, evaluated and corrected.

To analyze the overall indicator of "Level of IT Governance" (NGTI), must be analyzed individually the behavior of each predicates. Also could be analyzing the results for a group of companies globally. The scale was defined, considering the values of truth as follows:

Table 3. Scale Indicator

\begin{tabular}{|c|c|}
\hline Valores & Clasificación \\
\hline $1 \leq$ NGTI $>0,9$ & Very high \\
\hline $0,9 \leq$ NGTI $>0,8$ & High \\
\hline $0,8 \leq$ NGTI $>0,7$ & Medium \\
\hline $0,7 \leq$ NGTI $>0,6$ & Low \\
\hline $0,6 \leq$ NGTI $>0,5$ & Very low \\
\hline $0,5 \leq$ NGTI & Critical \\
\hline
\end{tabular}

The fuzzy predicate described above to assess the level of IT governance in a company was represented in a fuzzy tree, using Fuzzy Tree Studio tool.

Once designed the fuzzy tree in the system must be associate the data set. This can be entered manually, if it is applied to evaluating an individual company or can import a set of data from a file in Excel or plain text, for joint evaluations of a group of companies.

The performances of the proposed indicator are evaluated using a set of 93 enterprises in Cuba. The values of truth obtained for the whole data set and its qualitative classification according to the proposed scale it's shown in table 4. Also we shown the total companies evaluated under each category and the percentage represented.

Table 4. Results

\begin{tabular}{|c|c|c|c|c|c|c|c|c|c|c|c|c|c|c|}
\hline \multirow[t]{3}{*}{ Predicate } & \multicolumn{12}{|c|}{ Clasificación del nivel (Total / \%) } & \multicolumn{2}{|c|}{ Global Classification } \\
\hline & \multicolumn{2}{|c|}{ Very high } & \multicolumn{2}{|c|}{ High } & \multicolumn{2}{|c|}{ Medium } & \multicolumn{2}{|c|}{ Low } & \multicolumn{2}{|c|}{ Very low } & \multicolumn{2}{|c|}{ Critical } & \multirow[t]{2}{*}{ Value } & \multirow[t]{2}{*}{ Classification } \\
\hline & $\mathbf{T}$ & $\%$ & $\mathbf{T}$ & $\%$ & $\mathbf{T}$ & $\%$ & $\mathbf{T}$ & $\%$ & $\mathbf{T}$ & $\%$ & $\mathbf{T}$ & $\%$ & & \\
\hline Organization & 22 & 23,66 & 0 & 0 & 0 & 0 & 0 & 0 & 1 & 1,07 & 70 & 75,27 & 0,1923 & Critical \\
\hline $\begin{array}{c}\text { Strategic } \\
\text { alignment }\end{array}$ & 1 & 1,07 & 8 & 8,6 & 20 & 21,51 & 19 & 20,43 & 13 & 13,98 & 32 & 34,41 & 0,5485 & Very low \\
\hline $\begin{array}{l}\text { IT Risk man- } \\
\text { agement }\end{array}$ & 19 & 20,43 & 10 & 10,75 & 23 & 24,73 & 24 & 25,81 & 5 & 5,38 & 12 & 12,9 & 0,6861 & Low \\
\hline $\begin{array}{l}\text { Good practices } \\
\text { implementation }\end{array}$ & 5 & 5,38 & 6 & 6,45 & 1 & 1,07 & 2 & 2,15 & 3 & 3,23 & 76 & 81,72 & 0,0855 & Critical \\
\hline $\begin{array}{c}\text { IT Governan- } \\
\text { ce Level }\end{array}$ & 2 & 2,15 & 3 & 3,23 & 3 & 3,23 & 2 & 2,15 & 2 & 2,15 & 81 & 87,09 & 0,2805 & Critical \\
\hline
\end{tabular}




\section{Conclusion and future work}

In the current research we presented some early stage work in the compensatory fuzzy logic field and also show two application of it in the Cuban enterprise. The methodology to implement a fuzzy aggregation method allows us to define new global indicators supported in statistical and fuzzy approach. The fuzzy indicator "IT governance level", based on the use of fuzzy predicates and their representation through fuzzy trees, allows us to evaluate the IT governance considering its four main functions: strategic alignment, organization, risk management and best practices implementation.

As future works we propose develop a sensitive analysis to demonstrate the robustness of the indicator defined as well as the fuzzy operators choose to define the indicators in the aggregation methods.

\section{References}

[1] CERUTO CORDOVÉS, TAYMI \& ROSETE SUÁREZ \& ALEJANDRO \& ESPÍN ANDRADE, R. 2009. Descubrimiento de predicados a través de la búsqueda metaheurística.

[2] CERUTO CORDOVÉS, T. R. S., ALEJANDRO \& ESPÍN ANDRADE, RAFAEL. 2009. Descubrimiento de predicados a través de la búsqueda metaheurística.

[3] CRONBACH, L. 1951. Coefficient alpha and the internal structure of tests. . Psychometrika. [Online].

[4] DUBOIS D. Y PRADE, H. 1980. Fuzzy Sets and Systems: Theory and Applications. .

[5] DUBOIS, D. \& PRADE, H. 1985. Review of fuzzy set aggregation connectives. Information sciences. [Online].
[6] ESPÍN ANDRADE, R. F. G., EDUARDO LA LOGICA DIFUSA COMPENSATORIA: Una plataforma para el razonamiento y la representación del conocimiento en un ambiente de decisión multicriterio.

[7] ESPÍN, R. A. A. F., E G. 2009 a La Lógica Difusa Compensatoria: Una plataforma para el razonamiento y la representación del conocimiento en un ambiente de decisión Multicriterio, en Análisis Multicriterio para la Toma de Decisiones: Métodos y Aplicaciones. .

[8] ESPÍN, R. A. E. A. 2007 a. Hacia un enfoque normativo semántico de la Toma de Decisiones: nexos teóricos y experimentales de la Lógica Difusa Compensatoria, la teoría de la utilidad esperada y la teoría de prospectos.

[9] HOTELLING, H. 1993. Analysis of a complex of statistical variables into principal components. Education Psychological [Online].

[10] KAISER, H. 1958. The varimax criterion for analytic rotation in factor analysis. Psychometrika [Online].

[11] KONAR, A. 2000. Artificial Intelligence and Soft Computing: Behavioral and Cognitive Modeling of the Human Brain.

[12] LITTLE, R. \& RUBIN, D. 2002. Statistical Analysis with Missing Data.

[13] MARIN ORTEGA, P. G. Á. L. 2009. Contribución a la modelación de una arquitectura empresarial, para soluciones de inteligencia de negocios.

[14] NARDO, M., SALTELLI, A., SAISANA, M., TARANTOLA, S., HOFFMAN, A. \& GIOVANNI, E. 2005. Handbook on constructing composite indicators: Methodology and user guide. OECD Statistics Working Paper, STD/DOC . .

[15] PEARSON, K. 1901. On lines and planes of closest fit to a system of points in space. 